\title{
AS FALAS DO MEDO \\ Convergências entre as cidades do \\ Porto e Rio de Janeiro
}

\section{Ximene Rêgo \\ Luís Fernandes}

\section{Introdução}

Observar o distante encerra em si o potencial de revelar o familiar. Trata-se de um exercício em que se mobilizam para a observação e análise sucessivos momentos de estranhamento do objeto - o sentimento de insegurança. ${ }^{1} \mathrm{E}$ quando o olhar regressa ao ponto de partida, o Porto, é então altura de estranhar o familiar (Velho, 1981), antes assegurado, no Rio de Janeiro, pelo transporte para o terreno da parafernália de referenciais pessoais do etnógrafo, da qual ele não deixa todavia de tentar desfazer-se constantemente. A perspectiva comparada significa ir longe para ver mais perto: o Rio de Janeiro põe-nos a pensar o medo, o crime e a violência no Porto. Próxima e distante, essa experiência serve agora de mote a uma reflexão que integra uma investigação em

Artigo recebido em 07/08/2009

Aprovado em 20/09/2011 curso mais ampla - a imagem predatória da cidade: uma etnografia urbana do medo - a decorrer no Porto, trazendo-lhe uma vertente comparativa. ${ }^{2}$ Antes de avançarmos, gostaríamos de fazer uma aproximação concisa ao quadrante epistemológico que nos guiou, à hipótese de que partimos, ao âmbito do debate em que nos colocamos, este mais desenvolvido adiante, e, também, a alguns aspectos metodológicos.

Começamos por esclarecer uma premissa essencial, qual seja, a de que a relação entre crime e medo é complexa. O medo é, tal como outros estados emocionais, dependente de uma mesma base biológica comum. Sabemos da sua existência através da nossa própria experiência do dia a dia e da daqueles que nos rodeiam. Contudo, é também inteira e irremediavelmente social. Por incontornável que seja a sua concretude, o crime é alvo de uma construção social, cujo produto será, entre outros, o sentimento de insegurança. Mas o 
medo do crime é também relacional - ele vive nas e das relações sociais - e, nesse sentido, pertence ao campo das subjectividades. Assim se estabelece uma posição desvinculada de outras que equacionam a insegurança como reflexo linear da realidade criminal, ou como espelho da realidade interna dos sujeitos receosos, ou ainda daquelas que a tomam como produto criado pelas elites para melhor manipulação das massas.

Demarcando-se dessas posições que deixam um vazio por preencher, entre medo-fabricado e medo-espelho, alguns autores, e escolhemos um português e um brasileiro de forma a estreitar o diálogo, preferem conceitualizar o sentimento de insegurança como "um dado posicionamento interpretativo face à realidade criminal, discurso produtor de significados sobre o crime e a desordem" (Machado, 2004, p. 129). O medo e o discurso sobre o crime, portanto, não só produziriam interpretações e explicaçôes, como também organizariam a paisagem urbana e moldariam as interações sociais, restringindo os movimentos das pessoas e emagrecendo seu universo de interação (Caldeira, 2000).

É nesta linha de ideias que fomos sugerindo que o medo à cidade assentaria na relação que o urbanita estabelece e define constantemente com os ambientes implicados no seu quotidiano. Partindo do conceito de hipótese predatória, ${ }^{3}$ uma grelha de leitura das interaçôes com o Outro, assente na crença da perigosidade do espaço urbano, procuramos decifrar de que maneira os fenômenos da insegurança, da criminalidade e da violência concorrem para determinar a experiência urbana. Com impacto não só nos discursos, mas também nas práticas urbanas, a hipótese predatória constitui "um verdadeiro mecanismo atribucional para as relaçôes da vida quotidiana" (Fernandes, 2003, p. 59), retomando o protagonismo do Estranho, atribuído por trabalhos mais antigos (Skogan, 1977; Merry, 1981), nas relações anónimas que se desenrolam na cidade.

É no âmbito do debate em torno do paradoxo da insegurança - a ausência de correspondência na variação entre a taxa de criminalidade e o sentimento de insegurança - que deve ser inserida a análise que se segue. Para tal, servimo- -nos das falas do medo portuense e carioca. Nelas, procuramos analisar certos elementos discursivos: as representações dos lugares tidos como perigosos e a relação que se vai elaborando entre centralidades e espaços intersticiais, a construção de um imaginário povoado de figuras da ameaça, as estratégias securitárias mobilizadas para organizar o quotidiano num espaço público percebido como predatório. Se é registada, de um lado, a presença de afinidades na forma como o urbanita se adapta aos fenômenos da criminalidade, de outro, não é intenção fazer obscurecer as marcadas diferenças que atravessam os cenários da insegurança numa e noutra cidade. Pretende-se antes problematizar o discurso (in)securitário, recorrendo aos elementos que fazem a sua construção e salientando como determinadas dimensões podem ser próximas nesse cenário tão desigual. Desloca-se, portanto, o enfoque da questão da insegurança objetiva para a forma como ela é - subjetivamente - construída.

Como tem a hipótese predatória produzido modificações no quotidiano da cidade? Que ligações se esboçam entre as imagens da cidade e as práticas quotidianas? Por que a escolha dessas cidades, Porto e Rio de Janeiro? Analisar lado a lado contextos contrastantes permitirá relativizar questôes importantes em torno do tema. É nessa disparidade que fomos procurar meios de iluminar determinadas narrativas cujas distâncias não parecem ser as que se poderiam supor a partir das taxas da criminalidade expressa. Foi essa uma das constataçôes que nos levou a admitir o interesse em desenvolver um "programa genérico de investigação" (Fernandes, 2003, p. 60) que comparasse esses dois contextos. Com um estatuto simbólico inquestionável, são ambos o segundo polo de concentração de população e atividades econômicas dos respectivos países, desempenhando um papel de centralidade metropolitana e regional. São estas duas cidades, cuja legibilidade está intensamente marcada pela orla marítima, que são aqui convocadas à análise do medo. Porque o fato de a violência e o crime se estruturarem e expressarem de forma tão distinta deverá permitir aceder aos sentidos, consumando-se como um exercício de compreensão, 
tornado, pela língua comum, simultaneamente mais fácil e mais rigoroso.

As duas cidades confinam mais diferenças do que semelhanças. Não só pelas questóes mais óbvias de dimensão ou por seus passados que, embora se cruzem, seguem lógicas históricas distintas, mas também pelas realidades criminais tão díspares que obrigam a um cuidado meticuloso com os significados que, numa e noutra, são atribuídos à insegurança. Um olhar panorâmico sobre a vida das pessoas convidadas a falar é revelador nesse sentido. Nenhum dos entrevistados brasileiros havia escapado à experiência de ser vítima ou, ao menos, espectador de um crime. Em vários casos, essa experiência tinha-se repetido e quase sempre com recurso a armas de fogo. No Porto, essas situações são residuais.

Todavia, no Porto ou no Rio de Janeiro - é irrelevante - ser vítima de um crime corresponde quase sempre a um episódio breve, abrupto e inusitado. Essa peripécia possível tem o poder de pôr em causa a integridade física e/ou psicológica da pessoa. Independentemente da sua probabilidade estatística, esse incidente apresenta potencial fragmentador - o poder de suspender a realidade do quotidiano que, no decorrer dos afazeres mais mundanos, tomamos por garantida - e obriga-nos, conforme o conhecimento do senso comum, a tomá-la em consideração. Será precisamente a imprevisibilidade de que se reveste o crime predatório de rua, a probabilidade do imprevisivel, a verosimilhança de um mau encontro, um traço particularmente insecurizante da experiência urbana, e é este traço que, em certa medida, justifica a ansiedade que caracteriza o discurso em torno da (in)segurança. Está no nível do inescapável.

Mas se antes se falava de distância, há, por outro lado, que sublinhar a proximidade entre os dois contextos. A troca cultural mantém-se, se é que não se intensifica, não só nos tradicionais domínios musical e literário, do futebol ou das novelas, mas aos quais se juntam, para nomear somente alguns, o acadêmico e o cinematográfico (vale lembrar o impacto de filmes recentes como Cidade de Deus ou Tropa de elite), sem esquecer ainda que os brasileiros estão entre os contingentes de imigrantes de maior peso em Portugal.
Com trocas facilitadas pela crescente mobilidade das pessoas, das imagens e dos discursos, a cultura brasileira, mais do que qualquer outra, faz parte do cenário quotidiano português. Este intenso intercâmbio transatlântico faz-nos chegar imagens reificadas da cidade violenta. O cenário que nos vai sendo descrito é sinônimo precisamente daquilo que, urbanamente falando, receamos - a violência no Rio de Janeiro configura o nosso pior pesadelo de insegurança - traduzido na ideia de que isto está a ficar como o Brasil.

Pensadas no plural e numa lógica aproximativa, essas duas cidades orientaram a problematização num trajeto que nos fez descer da escala da cidade ao plano do etnografável. Tal jornada levou-nos a dois lugares particulares: à rua de Trás, na zona histórica e central do Porto, e à praça Pio XI, no bairro do Jardim Botânico, no Rio de Janeiro. Se investigações anteriores (Machado, 2004) têm apontado o centro do Porto, a par dos bairros sociais, como o locus privilegiado da expressão do medo, a Praça Pio XI foi alvo, em particular ao longo do ano de 2008, de uma série de assaltos muito mediatizados pela comunicação social. Mas pelo fato de as redes de relaçôes terem evoluído para lá dos lugares, o trabalho de campo não se confinou ali e as entrevistas conduzidas, com recurso ao método bola de neve, transbordaram para territórios adjacentes. No Porto foi ainda conduzido um conjunto de entrevistas na parte ocidental da cidade.

O material empírico mobilizado foi, então, constituído a partir da zona sul do Rio de Janeiro e do lado ocidental do Porto. ${ }^{4}$ Estes territórios distinguem-se por, quando comparados com a restante cidade ou com a área metropolitana, acumularem vantagens em certos indicadores sociais e econômicos: ocupação, rendimentos, educação formal ou condiçōes de moradia são alguns exemplos. ${ }^{5} \mathrm{~A}$ amostra, composta por sessenta indivíduos, ${ }^{6}$ pode ser definida por um conjunto de critérios que expandem a dimensão econômica propriamente dita: qualidade da habitação, capacidade de empregar terceiros ao seu serviço para tarefas domésticas, certos hábitos de lazer que incluem a participação na vida cultural e social da cidade (frequentar teatros, cinemas, exposiçōes, restaurantes), possibilidade de 
viajar para fora do país ou mesmo ter vivido fora por um período de tempo, formação superior e/ou ocupação intelectual. Trata-se de pessoas que detêm um considerável capital social e cultural, o que as coloca em posição de influenciarem as instâncias produtoras de discurso.

Quanto ao trabalho etnográfico, qualitativo e proximal por definição, ele assentou numa observação dos quotidianos, largamente baseado na postura do flâneur, operacionalizado através da observação direta e participante. As interações foram registadas em moldes pouco formais, como o diário de campo, ou com recurso à realização de entrevistas abertas e informais, cuja condução procurou respeitar o mais possível as condições naturalistas de registo que o método aconselha.

\section{A condição do urbanita}

Há certos tipos de multidão que te fazem sentir mais segura e certo tipo de multidão que te deixam mais insegura. Eu acho que multidões de lazer... numa rua mais movimentada num final de semana... me sinto um pouco mais segura do que numa rua do Centro movimentada em dia de semana (28 anos, estudante de pós-graduação, Botafogo, RJ).

Ainda que violência e crime tenham, numa e noutra cidade, uma estrutura e uma expressão muito distantes, as falas do medo permitem enunciar-lhes pontos de contato. Se o Rio de Janeiro se tem afirmado no cenário da insegurança e numa reputação à escala planetária como a cidade perigosa, evidenciando uma violência desagregante, Portugal tem-se feito anunciar como o nono país mais seguro do mundo e o terceiro da Europa com mais baixa criminalidade. ${ }^{7}$ Mas nem os dados que resultam da produção científica relativa ao sentimento de insegurança, disponíveis para o Porto, nem as notícias divulgadas pela comunicação social traduzem este cenário de paz social. Ainda que, quando comparado com o Rio de Janeiro, o Porto ofereça um panorama acanhado, a investigação tem descrito uma cidade que vive a insegurança de maneira intensa e generalizada
(Machado e Manita, 1999), sugerindo proporções mais graves do que o próprio crime. Ainda recentemente, o Observatório Local de Segurança do Porto divulgou que cerca de "metade dos portuenses tem medo de sair à noite" (Jornal de Notícias [JN], 9 jan. 2009).

Os media, por seu lado, ao mesmo tempo em que facilitam a circulação ininterrupta do rumor insecurizante, permitem anotar alguns elementos sobre os quais assenta a forma como o medo tem sido socialmente construído. Os principais jornais portugueses foram debitando ao longo do mês de agosto e primeiros dias de setembro de 2008 notícias que faziam supor ser o nosso um país marcado por uma imensa insegurança: os "Crimes violentos estão a aumentar em Portugal” (JN, 19 ago., capa) ou a "Criminalidade violenta assola o país” (JN, 23 ago., p. 6). Exigia-se, como é habitual em circunstâncias críticas, uma intervenção forte da parte do Estado e das forças de segurança diante do "notório aumento dos crimes violentos contra a propriedade" (Vital Moreira, JN, 23 ago., p. 6). O governo, o ministro da Administração Interna, a oposição, alguns autarcas, o diretor do Observatório de Segurança, Criminalidade Organizada e Terrorismo, o procurador-geral da República e o próprio presidente foram levados a pronunciar-se sobre o assunto. ${ }^{8}$ Assistimos, pois, no nono país mais seguro do mundo a uma pequena crise de pânico moral (Cohen, 1973), com o crime violento a constituir-se como uma ameaça excepcional à ordem social e os órgãos de informação, como agentes da indignação moral. Não interessa aqui discutir os números objetivos da criminalidade, um exercício complexo, sobretudo se nos quisermos servir de comparações entre diferentes países, ${ }^{9}$ mas não podemos deixar de notar que a evolução da criminalidade portuguesa e brasileira se reveste de particularidades quando a tentamos acomodar nas tendências mais gerais que marcam a maioria dos países democráticos e desenvolvidos do Ocidente. Nestes, verificou-se, entre as décadas de 1950 e 1970, um aumento da criminalidade de tipo aquisitivo (Cusson, 1990; Shelley, 1981), a par de uma outra tendência complementar, já anterior, que respeita à transformação gradual dos padrões da criminalidade (Lipo- 
vestky, 1983): ela deixa de estar maioritariamente concentrada nos crimes de interconhecimento, os crimes de sangue, e instala-se no seio das relações mais anônimas, sob a forma de crime predatório. Assim, ainda que com uma taxa superior àquela dos anos de 1950, a Europa vive taxas de crime violento inferiores às de meados do século XIX (Chesnais, 1982). Portugal apresenta certo desfasamento temporal - o crime contra a propriedade, sobretudo nas grandes áreas metropolitanas, cresce ligeiramente entre 1974, ano da queda da ditadura, e 1980, momento a partir do qual aumenta de forma acentuada (Santos et al., 1996). Quanto à transformação do padrão criminal, ele demora a instalar-se, com o homicídio no meio rural, mas não em meio urbano, a alimentar taxas mais elevadas de crime violento do que nos restantes países europeus (Fatela, 1988). Já o Brasil assiste, a partir de 1980, a um extraordinário aumento da criminalidade e, fato singular, do crime violento, circunstância que leva Angelina Peralva a salientar que o retorno à democracia ficou marcado "pela passagem das violências aquisitivas, cuja curva se havia elevado nos anos de 1970, aos crimes de sangue, cujas taxas mais do que dobraram entre 1980 e 1997, situando-se hoje entre as mais elevadas do mundo" (2000, p. 21). ${ }^{10}$

Este cenário de insegurança coletiva pode ser descrito a partir de quatro tendências que Sérgio Adorno (2002) descreve: o aumento do crime urbano contra o patrimônio e contra as pessoas; a emergência do crime organizado associado ao tráfico de drogas; a violação sistemática dos direitos humanos por parte das instâncias de controle social; e, por fim, o exacerbo do conflito no cerne das relações intersubjectivas, nomeadamente nas de vizinhança. A propósito do Rio de Janeiro, em particular, Gilberto Velho (2008, p. 27) serve-se de epítetos como desordem urbana, sensação de insegurança e medo da sociedade para descrever o quotidiano carioca, considerando que se trata de um "processo particularmente ameaçador à vida social". ${ }^{11}$

Mas Trajano Sento-Sé (2005) chama a atenção para um detalhe de maior relevância. Ele admite que o agravamento da criminalidade deu origem a uma forte sensação de insegurança, mas salienta que a percepção de que a violência afeta de forma transversal todos os segmentos da sociedade é falsa. O risco, ao contrário do medo, não está democraticamente distribuído. Ele se abate, sobretudo, sobre áreas geográficas onde está instalada a maior concentração de pobreza e a menor presença do Estado, atingindo especialmente jovens negros do sexo masculino. O sentimento de insegurança, esse, "aumenta o contingente daqueles que vivem como se estivessem efetivamente na iminência de se tornarem vítimas" (Idem, p. 11). Se em Portugal é o crime predatório de rua que faz a insegurança, no Brasil esta parece ser alimentada pelo crime mais violento, o que terá levado Luíz Eduardo Soares (1996) a falar de uma cultura do medo.

Uma vez no terreno, a primeira questão colocada foi, então, a do paradoxo da insegurança, extensamente discutido na literatura (Lupton e Tulloch, 1999). A disparidade entre medo sentido e crime praticado, ao menos de acordo com as estatísticas oficiais da criminalidade, torna difícil justificar por que é a criminalidade elegida como preocupação coletiva prioritária, em detrimento de outros fenômenos mais letais, sobretudo em países em que não atinge grande expressão, como é o caso de Portugal. Tal disparidade suscita análises que tendem a rotular o medo do crime de insensato, menosprezando-lhe a experiência vivida. O paradoxo da insegurança, a ser ultrapassado, pressupōe que o leigo, em qualquer circunstância em que se encontre, deva ser capaz de, tendo em consideração os números oficias, avaliar com adequação o grau de risco de ser vítima de um crime. Ou seja, pressupõe em cada cidadão comum um sujeito de escolha racional, sob pena de, não agindo assim, $o$ seu medo ser rotulado de desarrazoado. A propósito da proliferação das estratégias de controle do espaço, Cristina Patriota faz contrastar os casos dos Estados Unidos e do Brasil, em que regista a mesma tendência. Contudo, se no primeiro denuncia uma "incongruência entre riscos estatisticamente calculáveis e imaginários compartilhados pelo senso comum, no segundo diz ser impossível negar a existência real desta violência" $(2000$, p. 7). Na mesma linha, Alba Zaluar reitera que "o medo aqui [no Brasil] é, até certo ponto, um medo realista”, 
explicando que em face da multiplicação da taxa da criminalidade, não só aquisitiva mas também violenta, "não se pode dizer que o medo seja apenas uma criação do imaginário ou até mesmo da recepção passiva da mensagem" da comunicação social (2008, p. 213).

A análise do medo tende, independentemente do ponto do globo considerado, a fixar-se entre as reiteraçôes da sua presença e inquestionabilidade ou, no pólo oposto, a tratá-lo como mero exacerbo da inquietação individual ou coletiva. As vozes dos especialistas tendem a fazer o mesmo movimento pendular entre a adesão a um realismo irredutível ou a um construtivismo igualmente inabalável. Tomando de empréstimo o esquema de Cândido da Agra (2002), tais posiçōes remetem ora para a tese securitarista, ora para a tese construtivista. A primeira, pressupondo um nexo causal entre medo e crime, admite que o aumento daquele traduziria diretamente o aumento da criminalidade. A segunda salienta a irracionalidade do medo decorrente do discurso sociopolítico e da manipulação exercida pelos grupos hegemônicos. Do cruzamento entre uma e outra resulta um vazio por explorar, restando questionar o que é fato e o que é representação.

Eda Góes (2010) identifica no discurso político português essa mesma dinâmica. Se os partidos de direita estabelecem uma relação direta entre o aumento da delinquência e o da insegurança, os de esquerda salientam a sua dimensão subjetiva. São ambos, todavia, conservadores - os primeiros, em sintonia com o Broken Windows e as políticas de tolerância zero, que importam dos Estados Unidos; os segundos, denunciando o papel dos mass media e da segurança privada, que teriam interesses econômicos na ideia de que a insegurança se tem agravado. Ambos parecem ignorar dois aspectos determinantes: o aumento do medo, realizado principalmente à custa duma delinquência pouco relacionada com a ofensa corporal, e a ineficácia das forças de segurança pública para lhes fazer face.

Se Cristina Patriota propóe o abandono da lógica própria do discurso do medo via um exercício de estranhamento, nunca chega, todavia, a responder ao enigma que o paradoxo da insegurança coloca. É precisamente esse o exercício proposto. Aceitar que a relação entre medo e crime é direta, estabelecida na ausência de outros elementos mediadores, implica negar ao sujeito o seu espaço de autoria. Ele seria, nesse caso, uma tábua rasa na qual estaria escrito, linearmente, o ambiente criminal em seu redor.

O paradoxo da insegurança deve, então, ser apreciado de maneira cautelosa. Primeiro, porque não respeita ao leigo avaliar com precisão a probabilidade de, a um dado momento e num dado local, ser vítima de um crime. Depois, porque se entende que o móbil da ação reside nos significados que as pessoas atribuem às coisas, às suas realidades sociais, construídas segundo um processo de interpretação pessoal e sempre baseadas naquilo que as rodeia. Será nos aspectos mais mundanos da existência que o medo do crime tomará forma. Os discursos do medo relatados expressam pontos de contato nas estratégias a que recorrem para acentuar a "perigosidade" da cidade, sempre mais intensas no Rio de Janeiro, em que o tema da insegurança surge sem necessidade de ser elicitado, mas igualmente presentes nos discursos produzidos a partir do Porto. Trata-se de paralelos discursivos que, mais do que a partir das taxas de criminalidade divulgadas ou da experiência direta, se engendram a partir da relação com a cidade seus lugares e seus actores -, bem como das comunidades discursivas em que se inserem. Mais uma vez, que ligação se vai definindo entre as imagens que circulam sobre a cidade e a vida que nela se desenrola e as práticas diárias que se desdobram em torno do crime e da violência?

Se a experiência de insegurança não resulta inteiramente da taxa de criminalidade, talvez possamos situá-la nos novos modos de vida gerados pela cidade, cuja diversidade e troca proporcionadas parecem gerar dinâmicas ambivalentes, temas trabalhados por George Simmel no início do século $\mathrm{XX}$, para retornarmos a um dos fundadores destas temáticas. Não cabe aqui fazer-se a história do medo, mas há que sublinhar que o medo moderno é o medo do Outro, do encontro inopinado com o estranho, quadro que resulta da urbanização crescente - palco de existências diversas, forçadas a inventar novas convivências. A angústia gerada 
pelo encontro com o Outro situa a ameaça na própria urbanidade. É algo que parece residir na experiência de cidade e que sintetiza a condição do urbanita.

\section{A boa e a má cidade: modos de convivência}

Perigoso, cada lugar é um lugar diferente. Aí, Copacabana, quem mora perto da praia, tem uma tranquilidade, não tem problema nenhum dentro de casa, mora num prédio. Perigoso é para quem mora numa comunidade, numa favela. Aí tá lá, tá passando e do nada começa um tiroteio, perigoso é assim. [...] Fico sempre sozinho, senhora, eu ando sempre sozinho na rua. Dos caras, é maluqueira mesmo, se sabe que tu tá com dinheiro, já ficam nos cochichos um com o outro. Aí tu dorme, e para meter a mão, se sabe que tu vai acordar, até jogam uma pedra na tua cabeça para pegar as coisas que tu tá. A rua é assim, é terra sem lei. Qualquer um, qualquer um maluqueiro, se vê que tu tá com as coisas boas... (20 anos, morador da rua).

As falas descrevem uma topografia urbana do medo (Fernandes, 1994), sugerindo determinada coexistência entre a boa e a má cidade, ao mesmo tempo que impossibilitam a síntese da cidade numa imagem una. O Porto e o Rio de Janeiro têm a particularidade de fazer conviver, lado a lado, as populaçóes mais relegadas e as mais elitizadas, ao contrário de outras que foram empurrando para a periferia aqueles incapazes de encontrar para si um lugar na cidade. Comunidades como a Rocinha ou a Dona Marta, no Rio de Janeiro, e bairros de habitação social como o Aleixo ou o Pinheiro Torres, no Porto, ilustram essa convivência próxima. Sua tradução material num espaço-tempo anterior pode ser seguida na história das ilhas do Porto e dos cortiços do Rio (Seixas, 2003; Abreu, 1988; Valladares, 2005), numa correspondência direta com a innercity oitocentista, quando o perigo habitava o coração da cidade (Graham e Clarke, 2002). Dessa forma, ainda que a história da sua constituição conte uma aventura diferente, estes são lugares - favela e bairro - que, pelo valor simbólico que assumem na economia dos medos, são equivalentes enquanto figuras espaciais da ameaça. Numa espécie de hierarquia dos espaços perigosos, a favela e o bairro ocupariam, portanto, o lugar cimeiro, a que se segue depois a figura do centro. ${ }^{12}$

Mas a pesquisa também mostra como a percepção dos lugares do medo, dos seus atores e a mediação com eles esboçada pode ser descrita de uma forma muito mais fina, podendo inverter tal relação. Os lugares próximos, mais percorridos e integrados no quotidiano geram, muitas vezes, uma profunda angústia securitária: os primeiros são evitáveis, estes não. Aqui, os hábitos de relação com a cidade serão determinantes, e neles, o modo de morar (Velho, 2008). A passagem anterior ilustra-o bem. Se Copacabana é espaço da ameaça, reunindo grande consenso nos discursos construídos por moradores da zona sul, o morador de rua expressa precisamente o contrário: Copacabana é eleita por si como lugar da segurança por excelência. Copacabana é lugar do medo no contexto da zona sul, descendo imediatamente na hierarquia dos espaços perigosos quando a cidade é tomada como um todo.

Assim, permanece a oposição básica entre zona sul e o restante da cidade (zona norte, subúrbios, periferia, favela). A posição social a partir da qual é produzida a categorização revela, primeiro, o quanto ela pode ser relativizada, e, depois, que a insegurança não deve ser procurada na materialidade das coisas. Como qualquer etiqueta ou rótulo que se apõe a certos grupos ou lugares, como bem mostraram os sociólogos da teoria da etiquetagem, a atribuição de perigosidade resulta dos processos de interação simbólica produzidos no jogo de dominâncias entre os vários grupos sociais.

Os binômios morro-asfalto, no Rio de Janeiro, e bairro social-cidade ampla, no Porto, ainda que só existam dessa maneira dicotomizada na representação da cidade, tratando-se antes de uma dinâmica entre espaços com funcionamentos e, sobretudo, estatutos diferentes, determinam um modo de viver a cidade e a relação a estabelecer com os seus atores, prescrevendo, entre outras coisas, as categorias sociais a recear, os percursos a 
escolher ou os percursos a evitar. A concepção de cidade partida, título de Zuenir Ventura, foi amplamente criticada já que são múltiplas as trocas que se operam entre as diversas cidades dentro da cidade. Nesse sentido, Valladares descreve criticamente o "violento contraste entre o modo de vida dos pobres e o modo de vida dos ricos" (2005, p. 20), cuja representação considera uma generalização prematura e chama a atenção de autores, como Anthony Leeds, para quem essas comunidades estariam inequivocamente integradas no conjunto dinâmico da cidade. Fizemos também um exercício idêntico a partir do bairro social, procurando relativizar sua imagem dominante (Fernandes, 1994).

Esta desconstrução está muitas vezes vertida nos discursos produzidos no Rio de Janeiro, sinal de uma reflexividade já bem digerida por alguns: "a favela é só um sítio onde vive gente pobre, o que é ruim são os traficantes; $99 \%$ do povo da favela é honesto; na Rocinha tem estratificação social, há morador de rua, por vezes, você vê alguém de terno a sair para o trabalho"; e mesmo transportados para o Porto nas falas de quem lá viveu. Contudo, essa reflexividade dilui-se à medida que a imagem negativa destes espaços vai sendo retomada no aprofundar progressivo das entrevistas, e sua dimensão comunicante vai cedendo lugar à gestão das fronteiras sociais.

Os espaços perigosos já haviam sido identificados no imaginário urbano portuense - os bairros de habitação social e a zona histórica. Se o bairro aparece como concentração espacial da desviância, abrigando criminosos e ocultando crime - droga e violência -, o centro é, nesse imaginário coletivo, alvo preferencial dos agentes criminais que, a partir das zonas realmente perigosas, transitam para outras partes da cidade. São determinadas pistas ambientais - fraco policiamento, iluminação deficiente, incivilidades e, sobretudo, a desertificação (Machado, 2004) - que não só favorecem essa migração, como, pelas suas propriedades suscetíveis de gerar ansiedade, acentuam o receio. Crime, desordem e medo têm pois lugares, sejam periféricos, os bairros sociais, sejam centrais - o coração da cidade - pelo que o seu sentido é duplo: espacial e social. Os dados de terreno vão ao encontro do descrito:
Mais no centro [a insegurança] ... mas também há bairros em que é horrível. É mais o tipo de pessoas que vivem no centro... que não vivem, que vivem nesses bairros e que vão para o centro e no centro há mais gente e mais confusão para eles fazerem lá os roubos (76 anos, aposentada, Foz, Porto).

Um cenário idêntico foi sendo descrito a propósito do centro do Rio de Janeiro. Primeiro, a ideia de que, embora as favelas convivam com a restante cidade um pouco por toda a parte, o nosso lugar - a Lapa - seria no lado certo da cidade, a zona sul. Vai-se percebendo, depois, que estas primeiras informações não são unânimes. A própria ambiguidade na localização, em termos de sul ou centro, de áreas como a Lapa é, por si só, sugestiva. Num mapa mental muito esquemático, a cidade pode ser lida via duas categorias socioantropológicas distintas: zona sul (rica) e a zona norte (pobre), algo equivalente ao lado ocidental e ao lado oriental do Porto. ${ }^{13}$ São aquelas, a zona sul e o lado ocidental, que tendem a ser valorizadas pela qualidade de vida que inspiram (proximidade com o mar, sentido de ordem, equipamentos). O centro emerge com peso nos discursos, embora distinto daquelas na experiên cia de cidade que imprime. Já a Lapa e Santa Teresa poderão ter sua equivalência em algumas centralidades geradas no Porto, a partir da baixa e da zona histórica, constituindo-se como manchas de animação noturna. Ao longo do trabalho de campo a Lapa, na perspectiva que a localiza no centro, seria uma área com frequência de episódios, considerada perigosa, onde se deve ficar esperto.

Copacabana é um bairro que eu morro de medo; é a parte em que eu mais me sinto insegura no Rio de Janeiro, assim... da zona sul; porque é muita população de rua, muito pivete. Fora da zona sul... algumas partes do centro à noite, a Lapa, mais a Lapa... é o perigo do deserto. Para mim sair da zona sul já é perigoso. Ipanema está péssimo, não vai chegar a ser uma Copacabana, como Copacabana hoje é, mas está bem complicado... e o Leblon também. Onde tem gente com dinheiro tem assaltante. Tem assaltante em todo o lado, e se- 
gurança de esquina não garante nada, é tudo bandido também (28 anos, estudante de pós-graduação, Botafogo, RJ).

A zona norte, a zona sul e o centro têm, pois, pesos distintos na equação generalista da insegurança - sair da zona sul é sinônimo de perigo: a "zona do estádio do Maracanã tem policiamento, mas não há muita coisa por lá. Já tem história de bala perdida...". Verifica-se uma relação idêntica, ainda que menos severa, entre o lado ocidental e o lado oriental do Porto (Campanhã, Circunvalação...). Ora, admite-se que o medo do crime é, ao menos em parte, determinado por pistas contextuais do ambiente, sendo que a noção de ambiente urbano não está circunscrita a características físicas ou estritamente espaciais, incluindo também características ligadas à percepção dos aspectos sociais. $\mathrm{Na}$ passagem acima, a entrevistada morre de medo de Copacabana porque teme o tipo de população que por ali faz a sua deriva. Os sinais de ruptura física e social - janelas partidas, lixo por recolher, grafities, edifícios degradados ou abandonados, iluminação pública deficiente, grupos problemáticos que habitam o espaço público - inspiram receio, ao mesmo tempo em que traduzem a impotência das instâncias de controle. Estes sinais, de natureza material ou social, encontram-se diferentemente distribuídos no espaço e são sentidos como ameaça, insinuando que as normas sociais não são observadas (Taylor, 1989; Skogan, 1990).

São estas pistas que justificam parcialmente, do ponto de vista dos moradores da zona sul e do lado ocidental, a impressão de que a zona norte, o centro, Copacabana ou de que o lado oriental, a baixa e a zona histórica são áreas particularmente inseguras. Trata-se de um sentido ou de uma estética de ordem que emerge por oposição às expressões de desordem, uma forma de transgressão de ordem estética, prévia à transgressão de ordem ética (Fernandes, 1994). Essa transgressão, tão marcadamente visual, é rapidamente reconhecida, concorrendo para a identificação dos espaços potencialmente perigosos. A decadência do espaço público, a erosão das normas, que se reflete no comportamento das figuras do receio, apresenta-se como um sinal de ruptura da ordem social local. O crime e a delinquência não serão fenômenos dissociáveis de outros problemas que afetam a comunidade. São antes percebidos como parte da rede alargada de problemas sociais (Pain, 2000).

Parecendo querer servir o propósito de expressar com maior vivacidade a perigosidade da urbe, a totalidade da cidade é com frequência tomada como uma ameaça homogeneamente distribuída, estando o perigo disseminado por toda a parte. Quando o espaço público é tido na sua totalidade como sinônimo de espaço predatório, a impressão de risco acentua-se e todos os lugares são tidos como igualmente ilegíveis para a vitimização:

São todas inseguras; está muito complicado. Claro, perto da favela, perto de morro é mais perigoso, mas está generalizado. Está tudo perigoso. Não há zonas seguras (dona de casa, 60 anos, Lagoa, RJ).

Zonas perigosas, elas estão em todo o lado, porque se a senhora passa pela Banharia abaixo e não é conhecida é capaz de ter problemas, mas se for conhecida passa à vontade e ninguém lhe faz mal nenhum; por isso, o perigo está em todo o lado... em todo o lado o perigo está à espreita (ex-comerciante, 61 anos, Centro, Porto).

Os elementos insecurizantes mobilizados nos nestes excertos emergem especialmente nas narrativas que expressam maior preocupação com o tema da insegurança e denunciam uma mesma concepção de cidade - a de selva urbana. O perigo espreita em qualquer esquina, pressupondo a inexistência de bolhas de segurança acessíveis ao transeunte e, ao mesmo tempo, retirando qualquer eficácia aos mecanismos pessoais de prevenção do crime. Acentua-se igualmente a imprevisibilidade de que se reveste o crime predatório de rua. Mas o aprofundamento das conversas permite também desconstruir progressivamente a imagem do espaço público uniformemente perigoso, já que lhe está normalmente subjacente uma teoria pessoal acerca do crime e da violência, permitindo antecipar cambiantes no espaço urbano. 
Teresa Caldeira faz notar o simplismo dessas explicações. Talvez por isso estes sejam discursos tão frequentemente marcados por algum grau de contradição, já que "elaboram preconceitos e tentam eliminar ambiguidades (2000, p. 27). A mais saliente é a percepção da favela ou do bairro e suas imediações como o espaço mais perigoso e, em simultâneo, a impressão de que as zonas de maior poder aquisitivo são as mais visadas. Este elemento prende-se agora, e sobretudo, com uma autoatribuição do sujeito - ele se identifica como alvo preferencial para a vitimação. É nesta linha de ideias que a Foz, no Porto, ou o Bairro do Jardim Botânico, no Rio de Janeiro, emergem como espaços de perigo, embora inusitados, referidos unicamente por aqueles que lá moram.

Uma pessoa está mais sujeita e exposta. Eu não sinto isso, mas... com certeza há mais assaltos aqui do que nos outros sítios porque havendo mais gente rica há mais procura de vítimas, não é? (professora, 50 anos, Foz, Porto).

Este é um dos últimos bairros sem favela [bairro do Jardim Botânico]; a maioria tem um elevado poder aquisitivo, é gente com algum dinheiro. O bairro está visado. A cidade vive uma crise de insegurança e desigualdade. $\mathrm{O}$ morro está descendo (designer, 34 anos, Jardim Botânico, RJ).

Os excertos sugerem duas coisas, implicando desde logo o regresso ao tema da favela e do bairro: o morro é a ameaça - o morro está descendo - e são as franjas sociais de maior poder aquisitivo que o devem recear por estarem na sua mira. Em seguida, os entrevistados definem-se, com maior ou menor grau de consciência, como alvo e é daí que resulta sua impressão de insegurança. Tratar-se-ia da ameaça dos desventurados que, atentos a uma espécie de geografia do alvo, desceriam ao asfalto e definiriam suas vítimas em função do seu poder aquisitivo, já que a cidade vive uma crise de desigualdade. Aqui, além de implícita uma concepção explicativa da criminalidade, a desigualdade, encontra-se o rational para uma das práticas de prevenção situacional do crime mais ouvida e comum aos dois contextos o não parecer abonado.
Quando vou [ao centro] protejo-me: na carteira posso levar um máximo de 40 euros; não levo cartões; documentação - só levo fotocópias. Para andar à vontade, se não fico sob tensão, não descontraio. Aqui [na Foz] uso a minha carteira normal (76 anos, aposentada, Foz, Porto).

O medo enuncia lugares, mas também personagens e teorias explicativas do crime que antecipam o mapa urbano da segregação. Esse mapa aponta para toda uma zona do social marginal. É assim que as questôes acerca do sentimento de insegurança se cruzam com as da exclusão. Com base nestas teorias - droga, crise de valores, desigualdade social, consumismo - emergem certas figuras que equacionam concepções dicotômicas da realidade social, sempre periclitantes entre a norma e o desvio, entre a inclusão e a exclusão. Enfim, entre o centro e a margem social. É assim também que as falas do medo evidenciam uma rotação na imagem do pobre: de integrado na sociedade tradicional, aceitante resignado da sua condição, passa agora a pobre violento, revestindo um potencial de desumanidade - algo expresso na passagem a seguir.

Batiam na porta... D. Eloísa tinha uma relação de que ele era pobre, mas era um ser humano. Hoje, o pobre que mendiga não é visto como ser humano. Porque eles são violentos, eles assaltam. Se não têm uma arma, têm uma faca. Naquele tempo, não havia isso, hoje estão mais violentos porque tem droga (dona de casa, 60 anos, Lagoa, RJ).

Os relegados da cidade, essa amálgama de categorias do receio, o equivalente da underclass norte-americana (Wacquant, 1996), parecem fazer despertar dois tipos de emoções em equilíbrio precário: misericórdia e medo, cautela e pena, fazendo regressar a ideia de uma marginalidade de fronteiras indiscerníveis (Castel, 1996). Já o criminoso de classe média, a quem é feita referência nos dois contextos, surge sempre de maneira esmorecida. Seus contornos revelam pouca definição, sendo por isso de difícil identificação - a transgressão ética não é acompanhada pela transgressão estética. Aquelas fi- 
guras, ao contrário dos "indivíduos bem postos que assaltam e incomodam", e à semelhança dos lugares do medo que se lhes associam, são rapidamente reconhecíveis.

Entre medo e dó, sinceramente, as pessoas que têm um ar de farrapos humanos. Fazem pena, muitas vezes são muito novos e eu, por outro lado, penso assim: este não terá nada a perder, pode facilmente atacar-me. Do pedir ao investir não irá uma grande distância. Por outro lado, uma pessoa também ouve falar de indivíduos muito bem postos que assaltam e incomodam e que se sabem insinuar, mas esses, sinceramente, lembram-me menos (professora reformada, 67 anos, Lordelo do Ouro, Porto).

O bairro e a favela têm, pois, as suas faces públicas - o jovem, o consumidor de drogas, o pobre ou o excluído - integrando todos a galeria dos "perigosos". Em busca de participação nos circuitos comerciais e de lazer, a sua deriva leva-os à boa cida$d e$, onde se multiplicam tanto as oportunidades de interação como as de categorização. Pontualmente, são descritas dinâmicas de solidariedade mútua, mas não suficientes para exaurir os elementos acusatórios que compõem suas descrições.

O guna, que reifica o jovem portuense das periferias desqualificadas, associado ao consumo de drogas leves e à sua venda, pode ter seu equivalente no moleque ou no jovem infrator do Rio de Janeiro. Combinando com uma personagem flutuante que "habita uma zona de incerteza entre o ameaçador, o desordeiro e o criminal, é descrito por um conjunto de signos ligados ao vestuário", mas sobretudo por "uma gestualidade específica" (Fernandes e Pinto, 2008, p. 185). As falas descrevem-no como uma pessoa que "não é grossa, é abusada"; alguém que "vai fazer tudo para te tirar do sério, não respeita nada"; enfim, pessoas "que provocam muito".

$\mathrm{O}$ "mundo da droga", profundamente diabolizado no imaginário da insegurança, compõe uma espécie de síntese da ameaça, especialmente compreensiva e esquemática, organizando os elementos aqui descritos. A fratura entre bairro, favela e a malha urbana envolvente terá facilitado a instalação dos mercados retalhistas de drogas. A partir deles, emergem o junkie ou o "drogado" - aquele que "é capaz de tudo para arranjar a dose" - o arrumador de carros (flanelinha no Rio), o pivete, o soldado, o traficante, este raramente tido como ameaça direta, uma vez que o seu rendimento estará garantido fora do circuito do crime predatório de rua. Todos eles se recobrem de diferentes gradaçōes de perigosidade. Entretanto, a maioria dos moradores do bairro e da favela, mais ou menos integrados nas rotinas da cidade, parece incapaz de se fazer ouvir, restando-lhe o esforço de "limpeza simbólica", para utilizar as palavras de António Machado da Silva (2008, p. 15), a fim de ganharem "a confiança do Outro".

Vemos, assim, delinear-se de forma mais concreta a equação do medo à cidade, sendo alinhados um conjunto de elementos: os lugares do medo, as categorias da inquietação, as teorias pessoais explicativas do crime e da violência, que vão progressivamente tornando mais explícita a imagem predatória da cidade.

\section{Nota final}

A partir do paradoxo da insegurança, procurou-se chamar a atenção dos pontos de contato entre narrativas produzidas em lugares com realidades criminais muito díspares, salientando seus elementos comuns. No Porto e no Rio de Janeiro, a experiência do medo parece estar arreigada na própria estrutura do quotidiano, ditando modos de participação e organizando rotinas da vida ordinária.

O bairro social e a favela podem ser objeto de um exercício interpretativo. As cidades aqui em foco vão buscar elementos no seu lado crisíco, aspectos presentes em ambos, para construírem os fenômenos da insegurança. Se a história atual das grandes cidades tem exacerbado os fenômenos da exclusão e da dualização e se estes alimentam uma experiência urbana em que o sentimento de insegurança é central, então é natural que este seja intenso em lugares que, do ponto de vista da expressão direta do crime, são tão diferentes. Trata-se de elementos que tendem a girar em torno de expressōes ligadas à marginalidade e que mais não fazem do 
que expressar a ruptura da ordem local, fragmentando as rotinas da boa cidade, penetrando no que é local e moldando-o, compondo, enfim, fórmulas comuns.

$\mathrm{O}$ que aquelas figuras nos dizem sobre a vida nas grandes cidades? Falam-nos com certeza da crise urbana e de sua transformação. O Estado mostra-se incapaz de deter a pauperização daquelas franjas e assiste-se ao florescimento das economias informais e subterrâneas. As drogas, sobretudo quando consideradas sob o ângulo de temas como o "tráfico" e a "concentração de marginais", seriam o fio condutor que atrairia os debates mediático e político até estas zonas. Temos então as periferias a alimentar o discurso sobre a exclusão e o sentimento de insegurança. Trata-se de uma nova figura da ameaça, constituída de todos os elementos que desenham a cidade relegada, quadro que se exacerba a partir dos anos de 1980 e que constitui hoje objeto construído nos discursos sociopolítico e científico. O sentimento de insegurança é uma ressonância afetiva, vivida internamente, mas que espelha as transformações sociais, criando uma inquietação que se ancora no medo do crime, que revela a cidade como palco da crise. À medida que a insegurança - ou sua impressão - se agrava, ela vai minando o vínculo social. As classes médias retraem-se e temem uma cidade a duas velocidades: a boa e a má. A dessolidarização leva ao seu fechamento, à segregação de convivências, a processos de distinção. O sentimento de insegurança gera fraturas no tecido social e legitima estratégias de controle mais rígidas. $\mathrm{O}$ vínculo social é atingido.

$\mathrm{O}$ bairro e a favela produzem imagens que se desprendem de várias formas, circulando no espaço mediático. Mas a ideia contrária, mais difícil de tornar evidente, também é verdadeira. O rumor insecurizante retorna aos lugares dos quais se alimenta sob a forma de políticas sociais e securitárias. Há um duplo movimento. Depois de constituída, esta figura não deixou, até hoje, de ser o emissor de uma série de efeitos: lugar físico na cidade concreta, produz imagens que circulam alimentando as narrativas da perigosidade (efeitos simbólicos do plano material); lugar simbólico (locus que albergaria as novas classes perigosas), atrai sobre si a produção de efeitos materiais. O exemplo mais drástico é for- necido pelas operações de renovação urbana que fazem desaparecer bairros inteiros, operando deslocações populacionais de milhares de indivíduos (efeitos materiais do plano simbólico). Em suma, os lugares da cidade relegada são os sítios onde se torna e se retorna ritualmente sempre que temos de nos haver com a desordem e o crime: delas nos dizem que eles vêm de lá. E é para lá que vamos quando queremos mostrar serviço na eficácia policial no combate ao crime. Enfim, reatualizamos com elas um velho jogo: são as zonas e os atores da desordem que nos permitem alimentar nossas narrativas de ordem - para que tudo fique na paz possível numa cidade em que o sentimento de insegurança diz estar em guerra.

\section{Notas}

1 O tema é conhecido na literatura científica por dois nomes que remetem a tradições teóricas distintas: medo do crime e sentimento de insegurança. Embora o termo insegurança ou sentimento de insegurança tenha tido sempre maior ressonância no lado europeu, eles são atualmente usados como sinônimos.

2 O trabalho de campo decorreu no Porto entre 2007 e 2010. No Rio de Janeiro, dividiu-se em dois períodos intensivos de cinco semanas cada, um 2008 e outro em 2010. Deixa-se aqui um agradecimento especial a Rafael Oliveira pela sua incansável companhia no terreno carioca.

3 Os contornos da hipótese predatória foram, primeiro, conjecturados no contexto de uma visita ao Rio de Janeiro e descritos de maneira embrionária no livro Pelo rio abaixo (Fernandes, 2001). Mais tarde, deu forma ao artigo "A imagem predatória da cidade" (Fernandes, 2003) e foi desenvolvida com maior detalhe em "As bases ecossociais do sentimento de insegurança" (Fernandes, 2004). Por fim, esses textos emprestaram a expressão à tese de doutoramento, cujos dados servem à análise que se desenvolve aqui.

4 As entrevistas realizadas na rua de Trás não entram nesta contabilidade. Essa decisão baseou-se na necessidade de manter alguns critérios de homogeneidade social, econômica e demográfica, facilitadores da comparação. Pelo mesmo motivo, não foram contabilizadas as entrevistas realizadas fora da zona sul do Rio de Janeiro. Em todo o caso, sempre que o interesse o justifica, são utilizados alguns excertos delas. 
5 Para um retrato sociodemográfico do Porto, ver Pereira (2001); para o Rio de Janeiro, consultar Lago (2009) e, mais especificamente sobre a zona sul, ver a coleção Estudos da Cidade, 108 (2003).

6 Foram conduzidas 28 entrevistas no Porto (16 mulheres e 12 homens,) e 32 no Rio de Janeiro (18 mulheres e 14 homens). As idades variam entre 15 e 91 anos, mas se organizam em torno de uma idade média de 52 anos, no Porto, e de 42 anos, no Rio de Janeiro.

7 Dados divulgados pelo Economist Intelligence Unit do grupo da revista The Economist, em 30 de maio de 2008. O Brasil ocupa a $83^{\text {a }}$ posição nesse ranking composto por 121 países. A notícia deu origem a um artigo no site do MAI (<http://opiniao.mai-gov.info/ index.php?s=nono+pais+mais+seguro $>$ ), bem como uma ampla divulgação na comunicação social.

8 Algum do discurso institucional dado a conhecer pelo Jornal de Notícias: José Sócrates - "O primeiro-ministro reconheceu que a sucessão de crimes violentos 'criou um sentimento de insegurança'" no país, 2 set., p. 8; Ministro da Administração Interna - "Não fui de férias. Não perdi tempo", 23 ago., p. 6; autarca da Amadora - "Em algumas zonas, em certas horas, há quem tenha medo de sair à rua. É preciso aumentar as operaçōes de patrulhamento", 23 ago., p. 6; diretor do Observatório de Segurança, Criminalidade Organizada e Terrorismo - "A criminalidade violenta veio para ficar em Portugal”, 22 ago., p. 12; procurador-geral da República - "PGR quer apoio das polícias contra o crime violento”, 28 ago., p. 7; presidente da República - "A onda de assaltos e crimes violentos que se tem vindo a verificar no nosso país é uma coisa muito séria”, 28 ago., p. 6.

9 Os países variam grandemente na maneira de organizar os sistemas policial e judicial, de definir os conceitos legais e de recolher e apresentar os dados estatísticos. Dessa forma, a ausência de uniformidade nas definições de ofensa, na utilização de instrumentos de medição e numa metodologia de recolha de dados comum torna o esforço de comparação muito difícil. Ver Soucebook (2003 e 2006), disponível em <http:// www.europeansourcebook.org/> e Tavares e Thomas. "Statistics in focus: population and social conditions". Crime and Criminal Justice, 15, 2007. European Communities, disponível em <http://epp.eurostat. ec.europa.eu/cache/ITY_OFFPUB/KS-SF-07-015/ EN/KS-SF-07-015-EN.PDF>.

10 Como exemplo, é de mencionar que a taxa de homicídios na zona sul, a mais baixa de toda a região metropolitana do Rio de Janeiro, correspondia, em 2004, a 5 vezes a taxa média registada em Londres e a mais do dobro da registada em Nova York, respectivamente 16,7, 2,8 e 7,0 por 100 mil habitantes (Musumeci, Silva e Conceição, 2006).

11 Para um panorama histórico do medo no Brasil, ver Velho (2008a).

12 Definimos o centro do Porto pela composição entre baixa e zona histórica. Numa operação idêntica, consideramos também a Lapa e Santa Teresa quando é referido o centro do Rio de Janeiro.

13 Não se pretende tomar estes territórios pela cidade toda, nem presumir que essas categorias sejam homogêneas no que toca às franjas sociais que as habitam. Contudo, são estas zonas que emergem de forma sistemática nos discursos, sendo a zona sul e o lado ocidental as áreas mais investidas em termos de equipamentos urbanos, bem como de maior valor imobiliário. Henrique Muga (2002) retrata-o bem nos mapas cognitivos que elaborou a propósito do Porto.

\section{BIBLIOGRAFIA}

ABREU, Maurício. (1988), Evolução urbana do Rio de Janeiro. Rio de Janeiro, Jorge Zahar.

ADORNO, Sérgio. (2002), "Exclusão sociopolítica e violência urbana”. Sociologias, 4 (8): 84-135.

AGRA, Cândido. (2002), "Prefácio", in P. Robert, $O$ cidadão, o crime e o Estado, Lisboa, Editorial Notícias.

CALDEIRA, Teresa. (2000), Cidade de muros: crime, segregação e cidadania em S. Paulo. São Paulo, Editora 34.

CASTEL, Robert. (1996), "Les marginaux dans l'histoire", in S. Paugam (ed.), L'exclusion: ètat des Savoires, Paris, La Decouvert.

CHESNAIS, Jean-Claude. (1982), Histoire de la violence, Paris, Robert Laffont.

COHEN, Stanley. (1973), Folk devils and moral panics. St Albans, Paladin.

CUSSON, Maurice. (1990), Croissance et décroissance du crime. Paris, Presses Universitaires de France.

FATELA, João. (1988), O sangue e a rua. Lisboa, D. Quixote.

FERNANDES, Luís. (1994), “Topografia urbana do medo: 'os espaços perigosos"'. Revista do Ministério Público, 59: 11-27. 
. (2001), Pelo Rio abaixo: crónica duma cidade insegura. Lisboa, Editorial Notícias.

. (2003), "A imagem predatória da cidade”, in G. Cordeiro, L. Baptista e A. Costa (orgs.), Etnografias Urbanas, Oeiras, Celta.

. (2004), "Bases ecossociais do sentimento de insegurança”. Educação, Sociedade e Culturas, 21: 93-112.

FERNANDES, Luís \& PINTO, Marta. (2008), "Juventude urbana pobre e experiência de cidade: o guna como figura da ameaça”, in M. I. Cunha (ed.), Aquém e além da prisão: cruzamentos e perspectivas, Lisboa, Noventa Graus.

GÓES, Eda. (2010), "Os partidos políticos e a insegurança urbana em Portugal”. Oficina no 337, CES. Disponível em <http://www.ces. uc.pt/publicacoes/oficina/ficheiros/337.pdf>.

GRAHAM, Peggoty \& CLARKE, John. (2002), "Dangerous places: crime and the city", in J. Muncie. e E. McLaughlin (eds.), The problem of crime, Londres, Sage.

LAGO, Luciana. (2009), Como anda o Rio de Janeiro: observatório das metrópoles. Rio de Janeiro, Letra Capital.

LIPOVEVETSKY, Gilles. (1983), A era do vazio. Lisboa, Relógio d'Água.

LUPTON, Deborah \& TULLOCH, John. (1999), "Theorizing fear of crime: beyond the rational/ irrational opposition”. British Journal of Socio$\log y, 50$ (3): 507-523.

MACHADO, Carla. (2004), Crime e insegurança: discursos do medo, imagens do outro. Lisboa, Editorial Notícias.

MACHADO, Carla \& AGRA, Cândido. (2002), "Insegurança e medo do crime: da ruptura da sociabilidade à reprodução da ordem social". Revista Portuguesa de Ciência Criminal, 12: 80101.

MACHADO, Carla \& MANITA, Celina. (1999), "Percepções e figuras do medo na cidade do Porto", in Insegurança urbana na cidade do Porto: estudos interdisciplinares, vol. 2, Porto, Observatório Permanente de Segurança.

MERRY, Sally. (1981), Urban danger: life in a neighbourhood of strangers. Filadélfia, Temple University.
MUGA, Henrique. (2002), Representação social da cidade do Porto. Porto, CEAA.

MUSUMECI, Leonarda; SILVA, Gabriel \& CONCEIÇÃO, Greice. (2006), "Geografia da violência na região metropolitana do Rio de Janeiro - 2000 a 2005”. Boletim Segurança e Cidadania, 11, Cesec.

PAIN, Rachel. (2000), "Place, social relations and the fear of crime: a review". Progress in Human Geography, 24 (3): 365-387.

PATRIOTA, Cristina. (2006), "A fortificação preventiva e a urbanidade como perigo". Série Antropologia, 407.

PERALVA, Angelina. (2000), Violência e democracia: o paradoxo brasileiro. São Paulo, Paz e Terra.

PEREIRA, Virgílio. (2001), “O Porto em alguns dos seus diferentes estados: coordenadas para um breve reflexão sobre os processos de (re) composição social e territorial característicos da cidade do Porto nas últimas décadas do século XX", in M. Pinheiro, L. Baptista e M. Vaz, Cidade e metrópole: centralidades e marginalidades, Oeiras, Celta.

SANTOS, Boaventura, MARQUES, Maria, PEDROSO, Pedro \& FERREIRA, Pedro. (1996), Os tribunais nas sociedades contemporâneas: 0 caso português. 2 ed. Porto, Afrontamento.

SEIXAS, Paulo. (2003), "Ilhas e condomínios: crítica para uma cidade melhor", in P. Seixas, P. Santos e H. Araújo, Pluralidades portuenses, Porto, Civilização.

SHELLEY, Louise. (1981), Crime and modernization: the impact of industrialization and urbanization on crime. Southern Illinois University. SILVA, A. Machado. (2008), "Introdução", in A. M. Silva, Vida sob cerco: violência e rotina nas favelas do Rio de Janeiro, Rio de Janeiro, Nova Fronteira.

SKOGAN, Wesley. (1977), "Public safety and the fear of crime in large American cities, in J. Gardiner (ed.), Public law and public policy, Nova York, Praeger.

. (1990), Disorder and decline, Nova York, Free Press.

SOARES, Luiz. (1996), Violência e politica no Rio de Janeiro. Rio de Janeiro, Relume Dumará. 
SENTO-SÉ, J. Trajano. (2005), "Violência, criminalidade e medo: breve balanço de um quadro pouco alentador", in G. Velho, Ciência e estudos de violência, Rio de Janeiro, Academia Brasileira de Ciências.

TAYLOR, Ralph. (1989), “Toward an environmental psychology of disorder: delinquency, crime, and fear of crime", in D. Stokols e I. Altman, Handbook of environmental psychology, Nova York, John Wiley.

VALLADARES, Licia. (2005), A invenção da favela. Rio de Janeiro, FGV.

VELHO, Gilberto. (1981), "Observando o familiar", in , Individualismo e cultura: notas para uma antropologia da sociedade contemporânea, Rio de Janeiro, Jorge Zahar. . (2008), "Metrópole, cultura e conflito", in G. Velho (org.), Rio de Janeiro: cultura, politica e conflito. Rio de Janeiro, Jorge Zahar. . (2008A), "Medo e violência: uma temática interdisciplinar”. Trabalho apresentado no seminário Avanços e Perspectivas da Ciência no Brasil, América Latina e Caribe, Rio de Janeiro, dez.

WACQUANT, Loic. (1996), "L'underclass urbaine dans l'imaginaire social et scientifique américain", in S. Paugam (ed.), L'exclusion: ètat des Savoires, Paris, La Decouvert.

ZALUAR, Alba. (2008), "Crime, medo e política", in A. Zaluar e M. Alvito (orgs.), Um século de favela. 5 ed. Rio de Janeiro, Fundação Getulio Vargas. 


\section{AS FALAS DO MEDO: CONVERGÊNCIAS ENTRE AS CIDADES DO PORTO E RIO DE JANEIRO}

\section{Ximene Rêgo e Luís Fernandes}

Palavras-chave: Sentimento de insegurança; Narrativas; etnografia; Porto; Rio de Janeiro.

Tendo como ponto de partida o enigma do paradoxo da insegurança (a ausência de correspondência na variação entre a taxa de criminalidade e o sentimento de insegurança) é proposta uma reflexão em torno das falas do medo produzidas no Porto e no Rio de Janeiro, onde se desenvolveu trabalho de campo. Nesse sentido, são analisadas dimensões presentes no discurso da (in)segurança: as representações dos lugares tidos como perigosos e a relação que se vai elaborando entre centralidades e espaços intersticiais; a construção de um imaginário povoado de figuras da ameaça; as estratégias securitárias mobilizadas para organizar o quotidiano num espaço público percebido como predatório. As falas e as práticas registadas expressam pontos de contacto nas estratégias a que recorrem para acentuar a "perigosidade" da cidade, sempre mais intensas no Rio de Janeiro, mas igualmente presentes no material produzido a partir do Porto; paralelos que, mais do que a partir das taxas de criminalidade divulgadas ou da experiência direta, se engendram na relação com a cidade com os seus lugares e os seus atores permitindo, mesmo num cenário tão desigual, uma aproximação discursiva.

\section{SPEAKING OF FEAR: CONVERGENCES BETWEEN THE CITIES OF PORTO AND RIO DE JANEIRO}

\section{Ximene Rêgo e Luís Fernandes}

Keywords: Feelings of insecurity; Narrative; Ethnography; Porto; Rio de Janeiro.

Taking as starting point the riddle of the paradox of insecurity (the lack of correlation between the change in crime rate and sense of insecurity) we propose a reflection on the speaking of fear produced in Porto and Rio de Janeiro, where we have carried out fieldwork. In this sense, these dimensions are discussed in the discourse of (in)security: the representations of places seen as dangerous and the relationship that goes on between centers and interstitial spaces; the construction of an imaginary filled with threatening figures; the securitarian strategies deployed to organize the daily life in a public space perceived as predatory. Both the speaking and the practices registered express contact points in strategies used to accentuate the "dangerousness" of the city, always more intense in Rio de Janeiro, but also present in the material gathered in Porto, parallels that, more than from crime rates disclosed or from direct experience, are engendered in the relationship with the city - with its places and its actors - allowing, even in a setting so unequal, a discursive approach.

\section{LES DISCOURS DE LA PEUR: CONVERGENCES ENTRE LES VILLES DE PORTO ET DE RIO DE JANEIRO}

\section{Ximene Rêgo e Luís Fernandes}

Mots-clés: Sentiment d'insécurité; Narratives; Ethnographie; Porto; Rio de Janeiro.

Ayant pour point de départ l'énigme du paradoxe de l'insécurité (l'absence de correspondance dans la variation entre le taux de criminalité et le sentiment d'insécurité) cet article propose une réflexion sur les discours de la peur produits à Porto et à Rio de Janeiro, villes où ont eu lieu nos recherches sur le terrain. Nous analysons les dimensions présentes dans le discours de l'(in)sécurité: les représentations des lieux considérés dangereux et le rapport qui se construit entre centralités et espaces interstitiels; la construction d'un imaginaire peuplé de représentations de la menace; les stratégies sécuritaires mobilisées pour organiser le quotidien dans un espace public perçu comme prédateur. Les discours et les pratiques identifiés expriment des points de contact dans les stratégies employées pour accentuer la "dangerosité" de la ville, toujours plus intenses à Rio de Janeiro, mais également présentes dans le matériel produit à partir de Porto; de parallèles qui, bien plus qu’à partir de taux de criminalité divulgués ou de l'expérience directe, s'engendrent dans la relation avec la ville - avec ses lieux et ses acteurs - permettant, même suivant un scénario aussi inégal, une approche discursive. 